\title{
Co-seismic slip, post-seismic slip, and aftershocks associated with two large earthquakes in 1996 in Hyuga-nada, Japan
}

\author{
Yuji Yagi $^{1}$, Masayuki Kikuchi ${ }^{1}$, and Takeshi Sagiya ${ }^{2}$ \\ ${ }^{1}$ Earthquake Research Institute, The University of Tokyo, 1-1-1 Yayoi, Bunkyo-ku, Tokyo 113-0032, Japan \\ ${ }^{2}$ Geographical Survey Institute, 1 Kitasato, Tsukuba 305-0811, Japan
}

(Received November 29, 2000; Revised April 2, 2001; Accepted April 3, 2001)

\begin{abstract}
We analyzed continuous GPS data to investigate the spatial distribution of post-seismic slip associated with two large earthquakes of October 19 and December 2, 1996, in Hyuga-nada, Japan. We found that the moment release due to post-seismic events was comparable to the co-seismic moment release during the two earthquakes. The source parameters of the first post-seismic event are as follows: the moment release $=1.7 \times 10^{19} \mathrm{Nm}$; the maximum slip $=0.06 \mathrm{~m}$ at about $50 \mathrm{~km}$ northwest from the epicenter of the first earthquake; the characteristic decay time $(=$ final slip/initial slope $)=15$ days. For the second post-seismic event, the moment release $=2.0 \times 10^{19} \mathrm{Nm}$; the maximum slip $=0.13 \mathrm{~m}$ at about $15 \mathrm{~km}$ northwest from the epicenter of the second earthquake; the characteristic time $=100$ days. In both events, the slip vectors of the downgoing Philippine Sea (PHS) Plate on the SW-striking interplate boundary are directed west, in accordance with the co-seismic slip. It is also shown that the sites for co-seismic slip, post-seismic slip, and aftershocks do not overlap but complementarily share the plate boundary. This suggests that individual sites are characterized by their own constitutive laws, which may control modes of moment release as well as the entire sequence.
\end{abstract}

\section{Introduction}

On October 19, 1996, a large thrust earthquake $(M s=6.7)$ occurred in Hyuga-nada, located at the southern extension of the Nankai trough. About two months later, on December 2 , another large thrust earthquake $(M s=6.7)$ occurred in the adjacent area. In Hyuga-nada, the PHS Plate subducts northwest beneath the Eurasian Plate at a rate of about 40 $70 \mathrm{~mm} /$ year (Seno et al., 1993), and the two earthquakes are consistent with release of stress buildup on the interplate boundary.

Fore-shocks, main-shocks, and aftershocks are shown in Fig. 1. The aftershock area of the first earthquake seems to have been re-activated by the second earthquake. Yagi et al. (1999) studied the co-seismic rupture and the aftershock area, and proposed that the aftershock area plays the role of a barrier to dynamic rupture. They also pointed out the occurrence of significant post-seismic surface displacements measured by geodetic instruments associated with these earthquakes. Thus far, such phenomena have been observed after several earthquakes (e.g., Smith and Wyss, 1968; Stein and Lisowski, 1983; Shen et al., 1994; Heki et al., 1997). Heki et al. (1997) interpreted the post-seismic displacements in terms of a slow slip expanding over the co-seismic fault plane. Post-seismic slip must readjust the stress distribution around the seismogenic zone, and affect the occurrence of future earthquakes (Segall et al., 2000). Scholz (1990) suggested that slow slip may be restricted to an area where dynamic rupture is impeded.

Copy right (C) The Society of Geomagnetism and Earth, Planetary and Space Sciences (SGEPSS); The Seismological Society of Japan; The Volcanological Society of Japan; The Geodetic Society of Japan; The Japanese Society for Planetary Sciences.
The 1996 Hyuga-nada earthquake is the first large earthquake since the high density network of continuous GPS was established over the Japanese islands by the Geographical Survey Institute (GSI) (Tada et al., 1997). The network has provided us with high-quality continuous data of crustal movement. In this paper, we use these data to investigate the spatial distribution of post-seismic slip. Then, combining the co-seismic fault motions, we examine the distribution of moment release at various stages.

\section{Data}

\subsection{Data processing}

We collected displacement-vectors recorded at the continuous GPS network of GSI and extracted the horizontal components on Tsushima Island station (Fig. 2). From the raw data, we extracted the net displacement due to fault motions in the following way. The observed coordinates of the $j$-th point at time $t, G_{j}(t)$, contains the initial position $A_{j}$, the secular motion $B_{j} t$, the fault-slip-originated motion $S_{j}(t)$, the local benchmark motion $L_{j}(t)$, and the observation error. The local benchmark motion is treated as a spatially incoherent Brownian random walk with a time-dependent variance given by a scale parameter $\tau$ (unit: [length/time $\left.{ }^{(1 / 2)}\right]$ ) (Wyatt, 1982, 1989; Langbein and Johnson, 1997). The observation error, on the other hand, comes from two sources: the instrumental instability at each GPS site $e_{j}(t)$ with a time-independent variance of $\sigma$, and the observation error at a reference station $E(t)$. Thus, the continuous GPS coordinate $G_{j}(t)$ can be represented as

$$
G_{j}(t)=A_{j}+B_{j} t+S_{j}(t)+L_{j}(t)+e_{j}(t)+E(t) .
$$




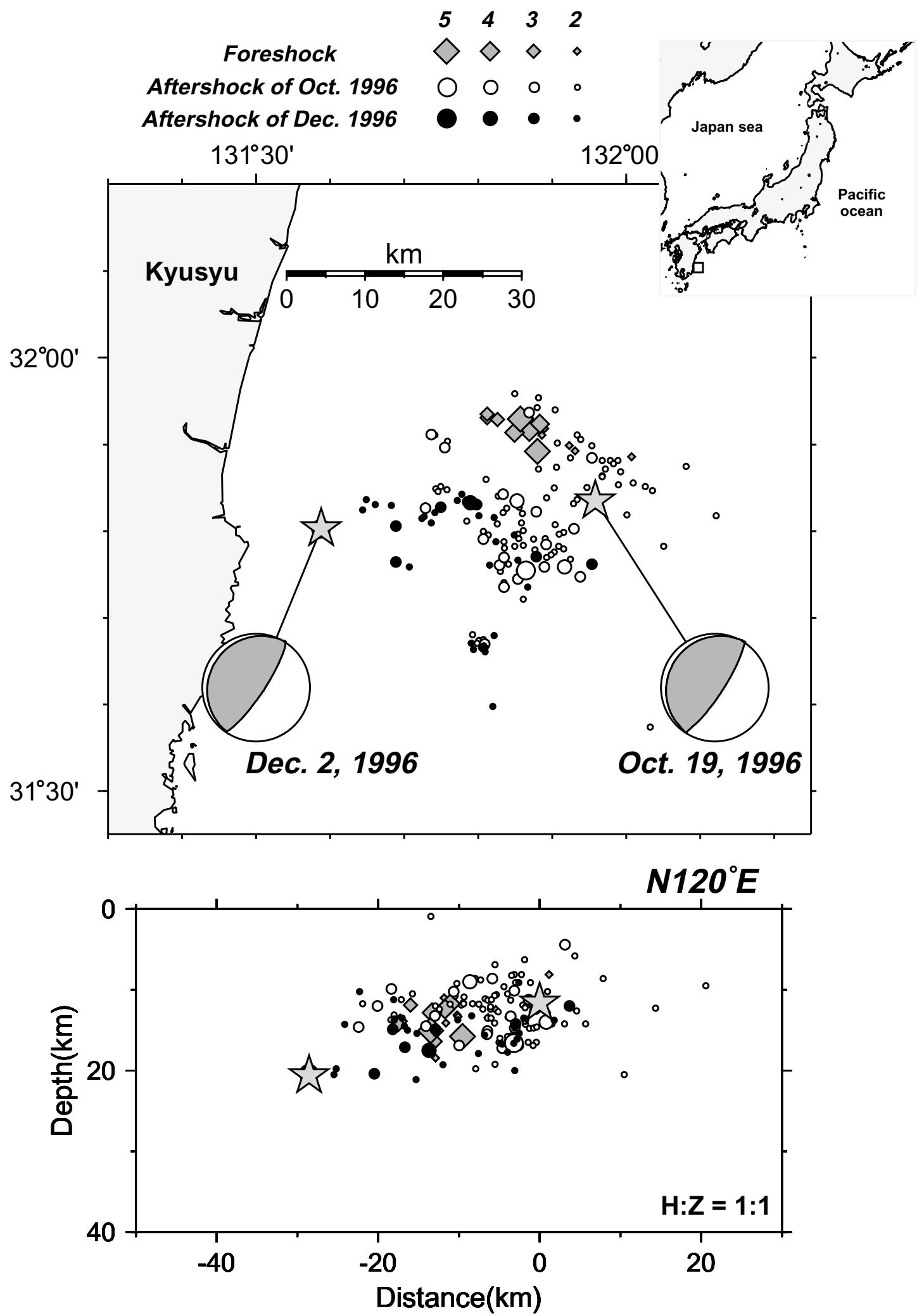

Fig. 1. Foreshocks (gray diamonds), one-week aftershocks (open circles) of the Hyuga-nada earthquake of October 1996, and one-week aftershocks (solid circles) of the Hyuga-nada earthquake of December 1996 as determined by the Shimabara Earthquake Volcano Observatory, Faculty of Science, Kyushu University. The focal mechanisms are determined by the joint inversion of GPS data and near-field strong ground motion (Yagi et al., 1999). 
Here we want to extract $S_{j}(t)$ from observed $G_{j}(t)$. To this end, we first take a simple stack of the GPS displacements over all stations in Japan. From Eq. (1), we obtain

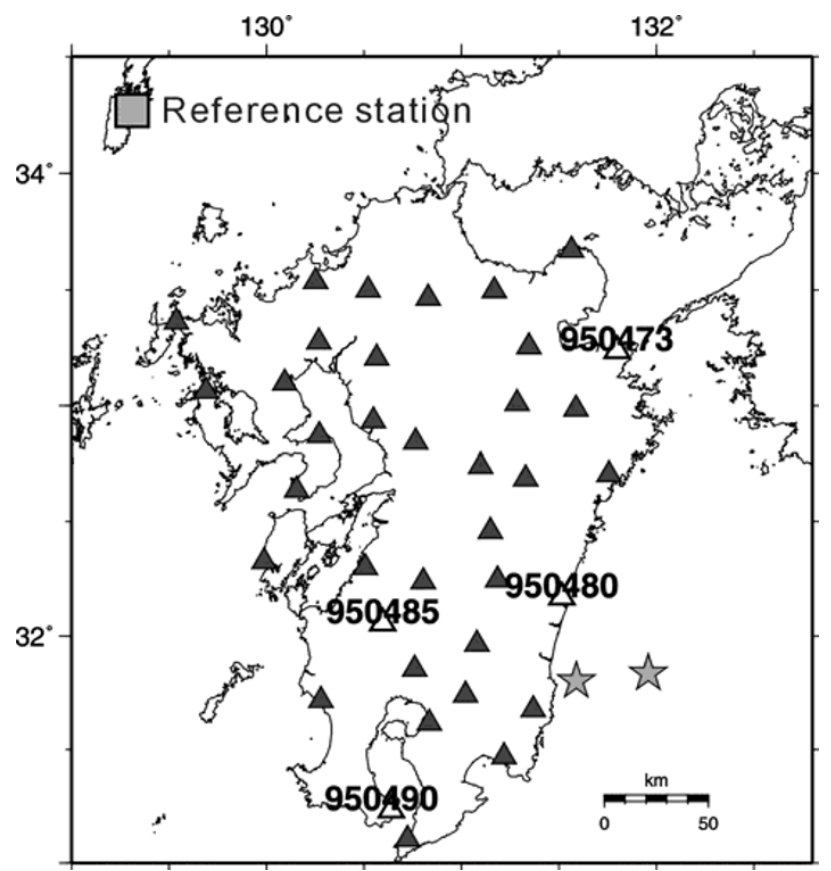

Fig. 2. GPS stations used in the geodetic inversion are denoted by triangles. Stars and square indicate the epicenters of the two main shocks and the reference GPS station, respectively.

(a)

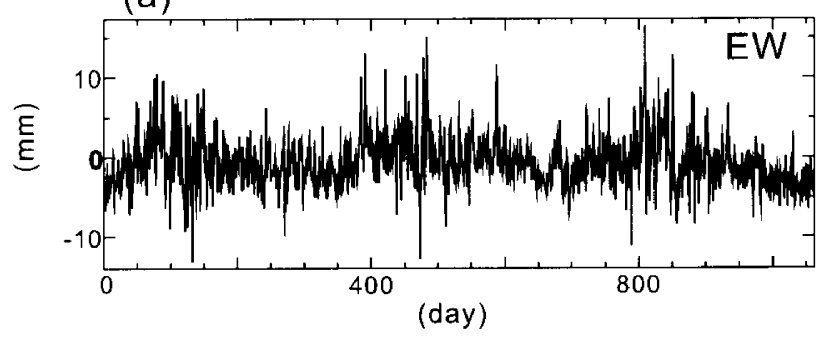

(b)

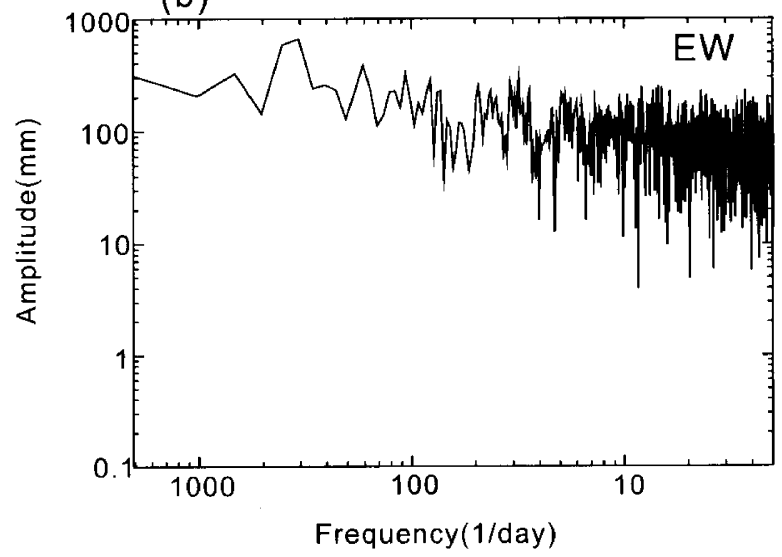

$$
\begin{aligned}
\frac{1}{N} \sum_{j=1}^{N} G_{j}(t)= & \frac{1}{N} \sum_{j=1}^{N}\left(A_{j}+B_{j} t\right)+\frac{1}{N} \sum_{j=1}^{N} S_{j}(t) \\
& +\frac{1}{N} \sum_{j=1}^{N}\left[L_{j}(t)+e_{j}(t)\right]+E(t) .
\end{aligned}
$$

Given that the fault-slip-originated displacement $S_{j}(t)$ is localized and the third term $L_{j}(t)+e_{j}(t)$ is spatially incoherent, these terms, after having been stacked over all stations in Japan, become negligible:

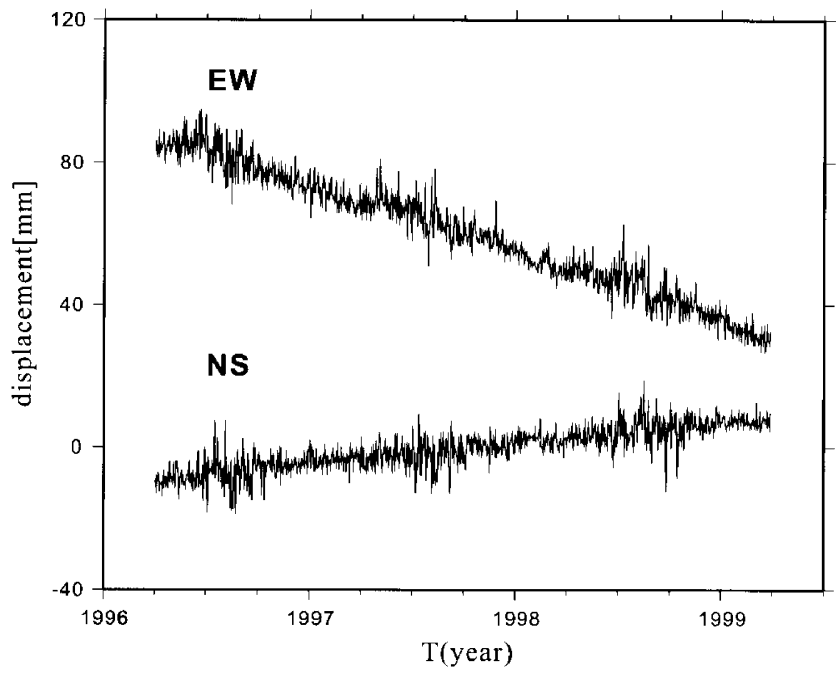

Fig. 3. The continuous GPS displacements stacked for all stations in Japan

(c)

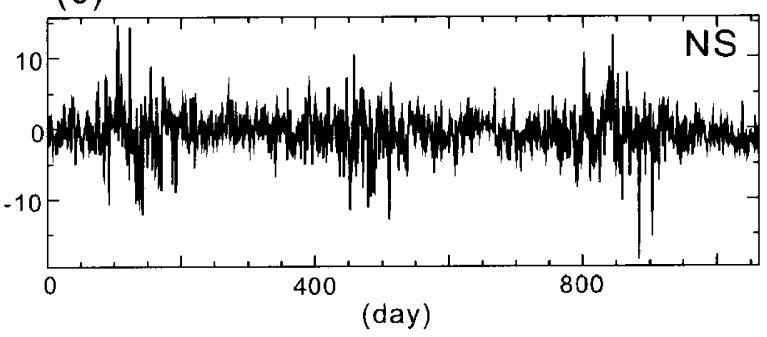

(d)

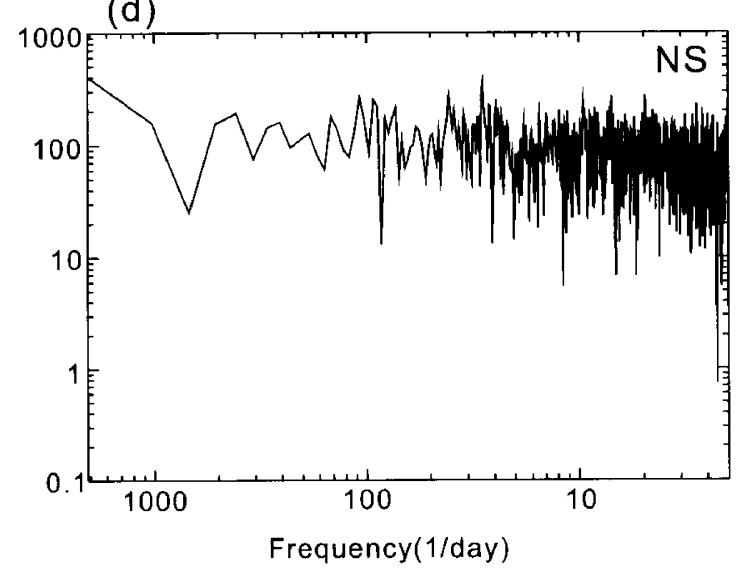

Fig. 4. (a) EW component of a coherent observation error, $E(t)$, (b) its amplitude spectrum, (c) NS component of $E(t)$, and (d) its amplitude spectrum. 
(a) NS component (raw data)

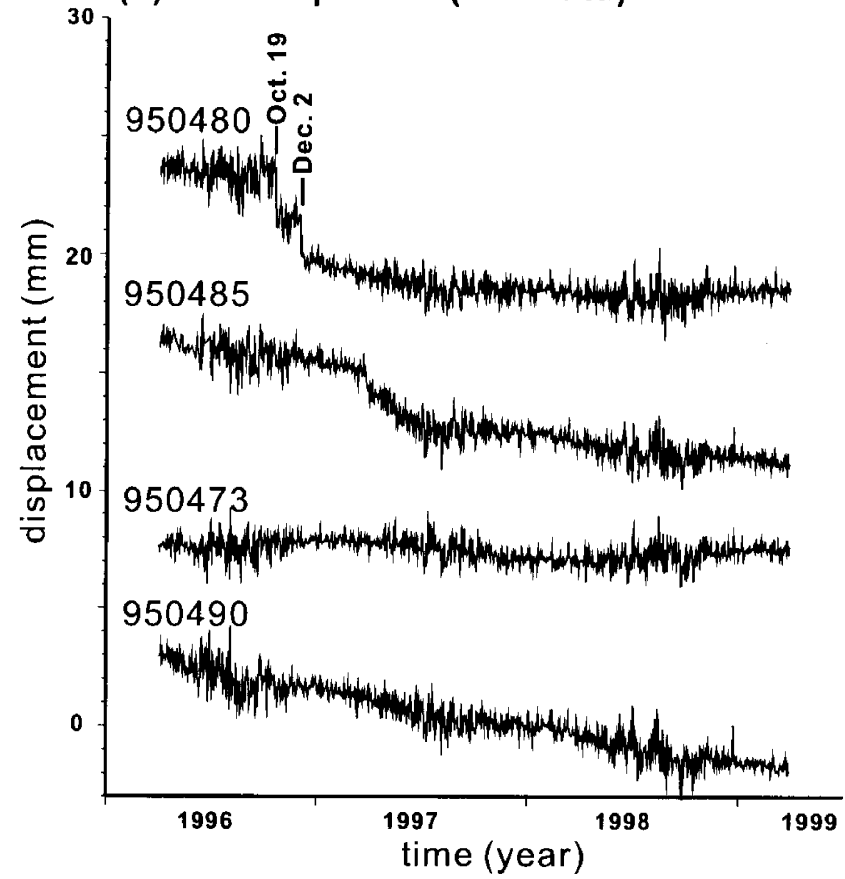

(c) NS component (processed data)

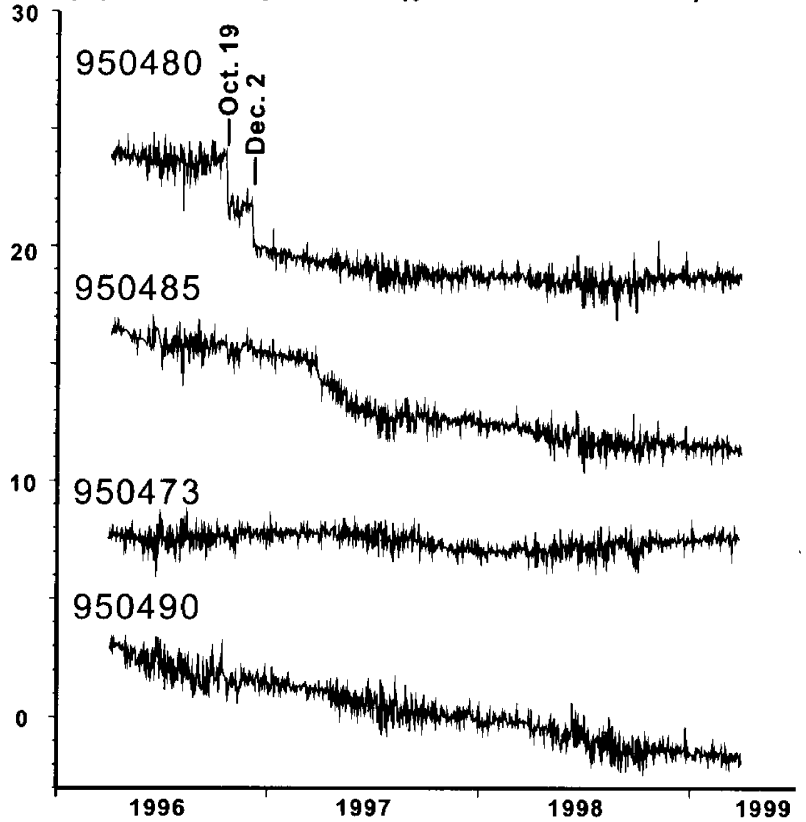

(b) EW component (raw data)

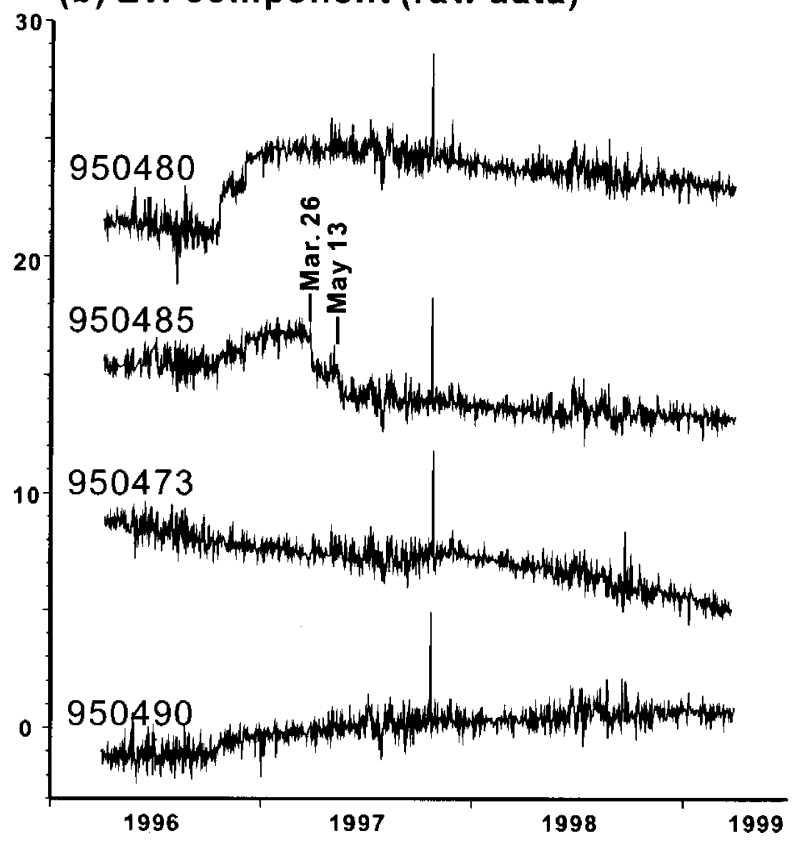

(d) EW component (processed data)

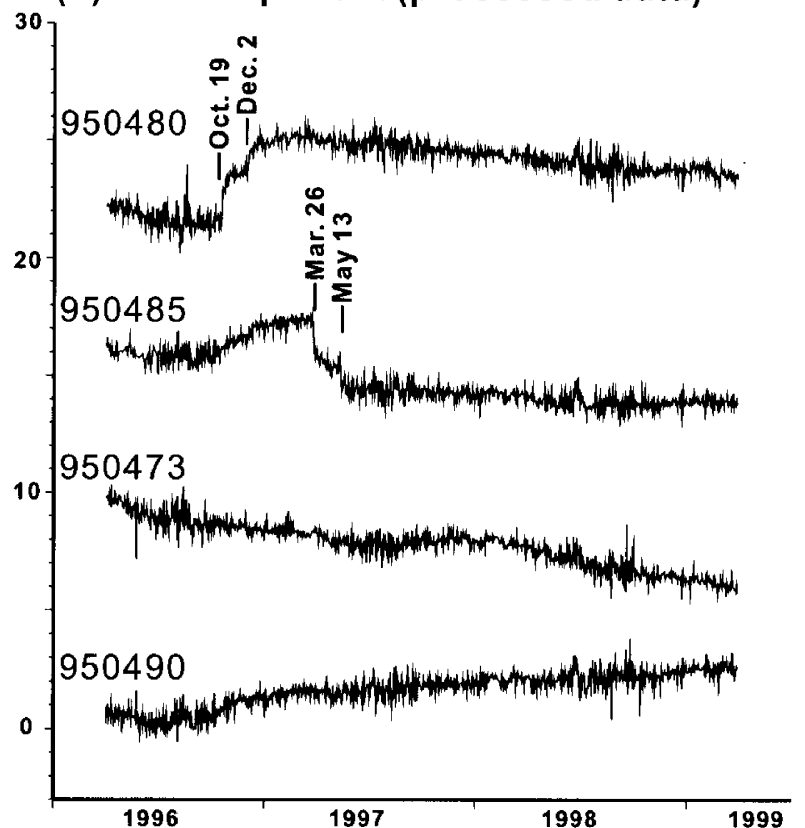

Fig. 5. Comparison of raw GPS data with the corrected displacement (a) raw NS component, (b) raw EW component, (c) the corrected NS component, and (d) the corrected EW component

$$
\frac{1}{N} \sum_{j=1}^{N}\left(S_{j}(t)+L_{j}(t)+e_{j}(t)\right) \approx 0 .
$$

Then Eq. (2) can be approximated as

$$
\frac{1}{N} \sum_{j=1}^{N} G_{j}(t) \approx \frac{1}{N} \sum_{j=1}^{N} A_{j}+\frac{1}{N} \sum_{j=1}^{N} B_{j}+E(t) .
$$

Figure 3 shows the stacked displacement. We can estimate the first and second terms on the right-hand side of (4) by a line fitting, and determine the observation error, $E(t)$. Fig- ure 4 represents the $E(t)$ thus obtained and its spectrum. Because the spectrum is nearly flat without any special peak, we regard $E(t)$ as a white noise.

Figure 5 compares raw data with the corrected displacement: $G_{j}^{c}(t)=G_{j}(t)-E(t)$ at several stations. At 950480 station (Fig. 2), co-seismic and post-seismic displacements are clearly identified for both Hyuga-nada earthquakes. At 950485 station, the co-seismic displacements associated with the Kagoshima earthquakes of March 26 and May 13 in 1997 are identified. The post-seismic displacement is barely identified for the March Kagoshima earthquake, though it is not 
(a) Oct. 96 co-seismic

$$
130 \quad 132
$$

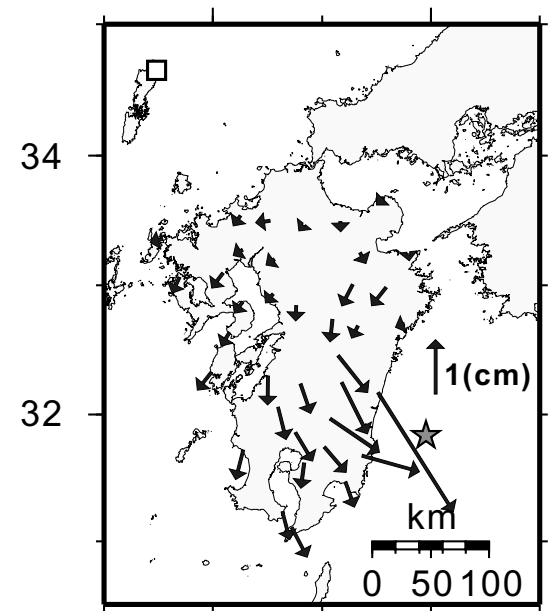

(d) Dec. 96 post-seismic

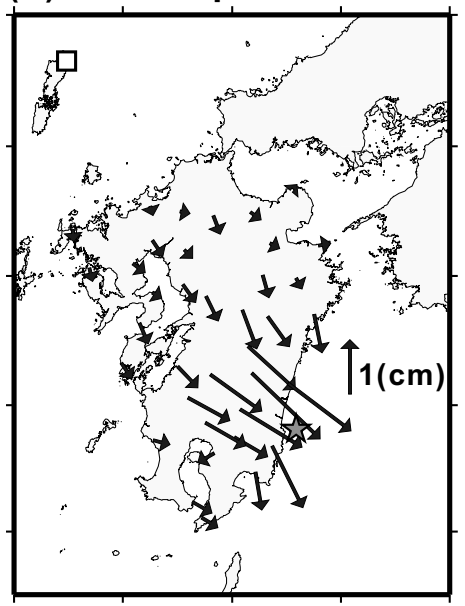

(g) May 97 co-seismic

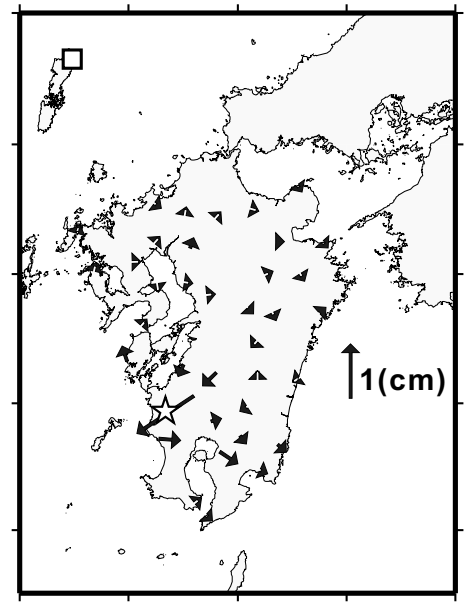

(b) Oct. 96 post-seismic

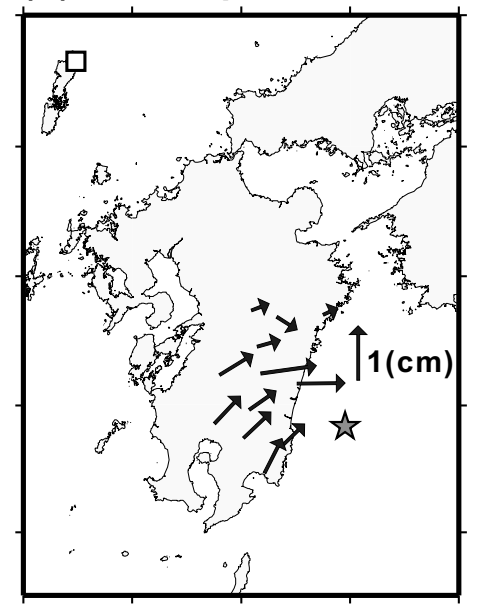

(e) Mar. 97 co-seismic

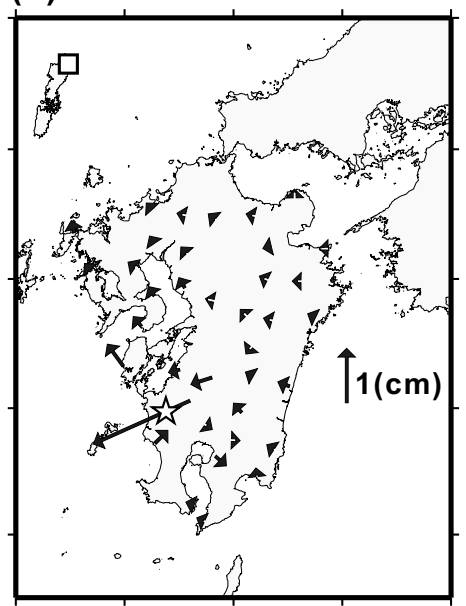

(h) Apr. 97 slow slip



(c) Dec. 96 co-seismic

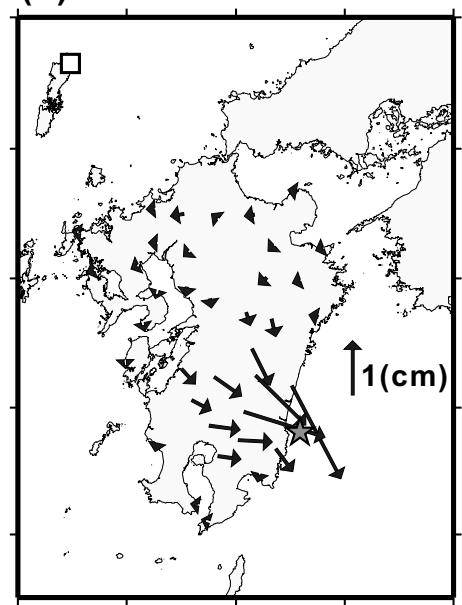

(f) Mar. 97 post-seismic

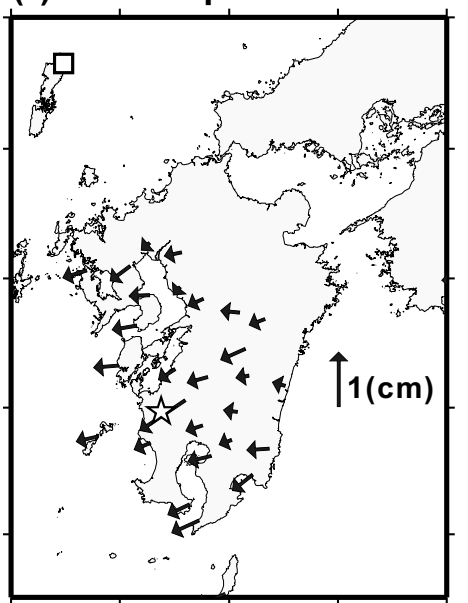

(i) Secular motion

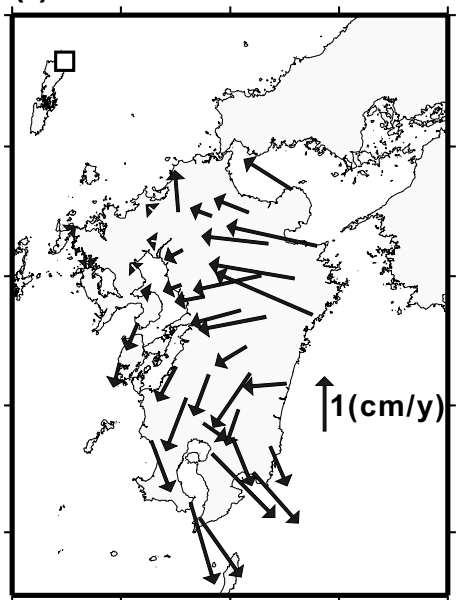

Fig. 6. Displacement vectors converted to elements. (a) co-seismic displacement at the Hyuga-nada earthquake of October $19,1996\left[X_{1 j}\right]$, (b) post-seismic displacement after the 1996 October earthquake $\left[Y_{1 j}\right]$, (c) co-seismic displacement of the Hyuga-nada earthquake of December $02,1996\left[X_{2 j}\right]$, (d) post-seismic displacement after the 1996 December earthquake $\left[Y_{2 j}\right]$, (e) co-seismic displacement at the Kagoshima earthquake of March 26, 1997 $\left[X_{3 j}\right]$, (f) post-seismic displacement after the 1997 March Kagoshima earthquake $\left[Y_{3 j}\right]$, (g) co-seismic displacement at the Kagoshima earthquake of May 13, $1997\left[X_{4 j}\right]$, (h) displacement associated with a slow event starting on July 18, $1997\left[Y_{5 j}\right]$, and (i) linear trend [ $\left.B_{j}\right]$. 

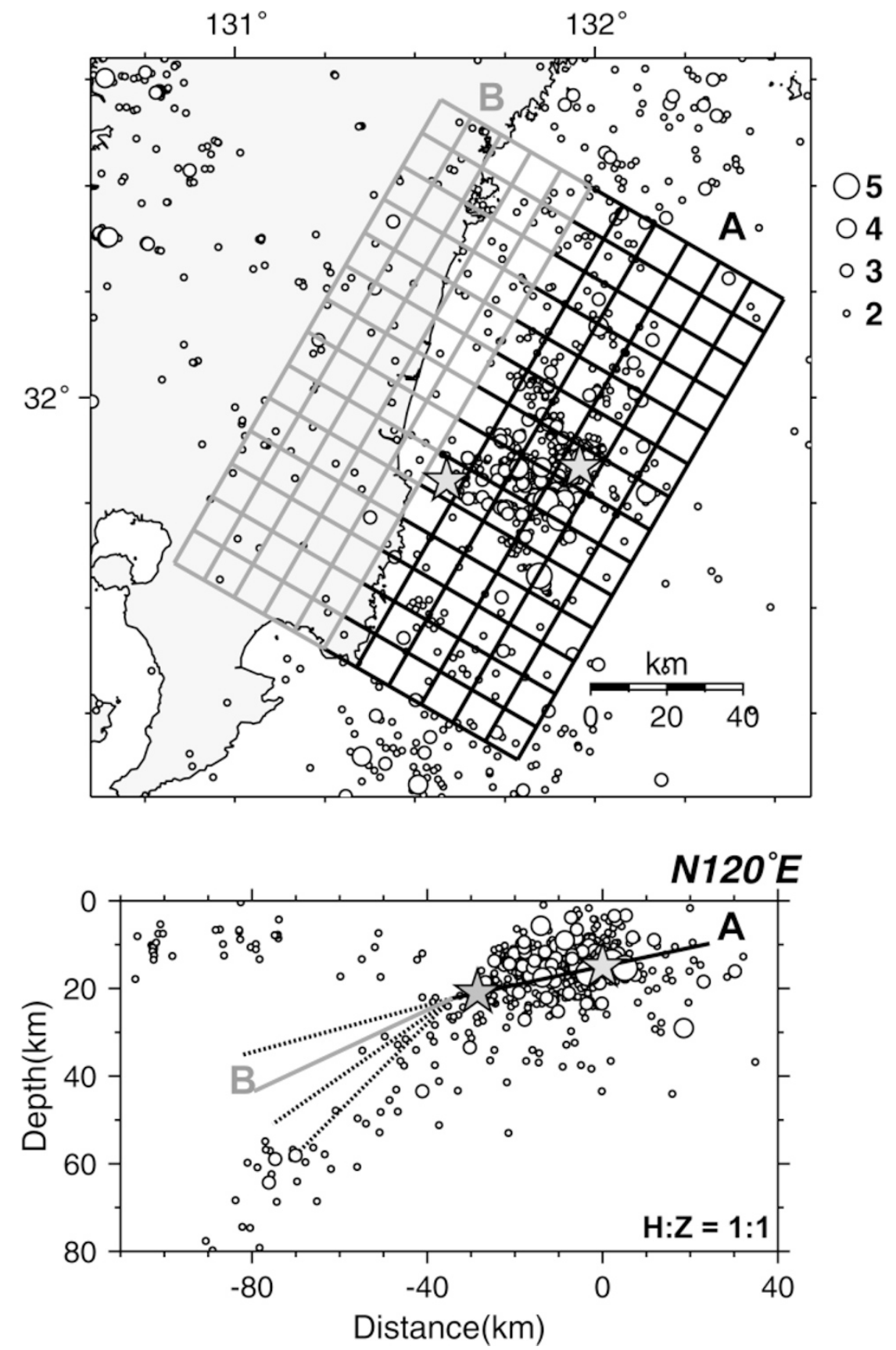

Fig. 7. Map view of assumed fault plane and background seismicity. Solid line represents the segment A. The dashed lines represent the candidates of segment B in grid-search. The gray line represents the best solution (dip angle of $25^{\circ}$ ).

identified for the May earthquake. At 950473 station, which is located about $100 \mathrm{~km}$ north of the first earthquake, a slow transient movement is clearly seen. In southern Kyusyu, a linear trend, as shown at 950490 station, is noticeable.

\subsection{Decomposition of displacement vectors}

In order to decompose the GPS data into fault-slip-originated displacements, we assume that the co-seismic displacements are represented by Heaviside step function $H(t)$, and the displacements due to post-seismic and slow events are represented by an exponential relaxation function $\{1-$ $\exp (-t / T)\}$ where $T$ is a characteristic rise time, which means (final-slip/initial-velocity). Considering that in Kyushu the GPS displacements contain only a slight seasonal component, we describe $S_{j}(t)$ as

$$
S_{j}(t)=\sum_{i=1}^{5} H\left(t-t_{i}\right)\left(X_{i j}+Y_{i j}\left\{1-\exp \left(-\left(t-t_{i}\right) / T_{i}\right)\right\}\right)
$$

where $t_{i}$ indicates the source origin time of the $i$-th event, $T_{i}$ the characteristic time, $X_{i j}$ the co-seismic displacement, and $Y_{i j}$ the final step of post-seismic displacement. Specific events are denoted by $i$ as

$i=1$ for the Hyuga-nada earthquake of Oct. 19, 1996,

$i=2$ for the Hyuga-nada earthquake of Dec. 02, 1996,

$i=3$ for the Kagoshima earthquake of Mar. 26, 1997 ,

$i=4$ for the Kagoshima earthquake of May 13, 1997, and

$i=5$ for a slow slip event starting on Jul. 18, 1997.

Given that the slow event is not accompanied by any co- 


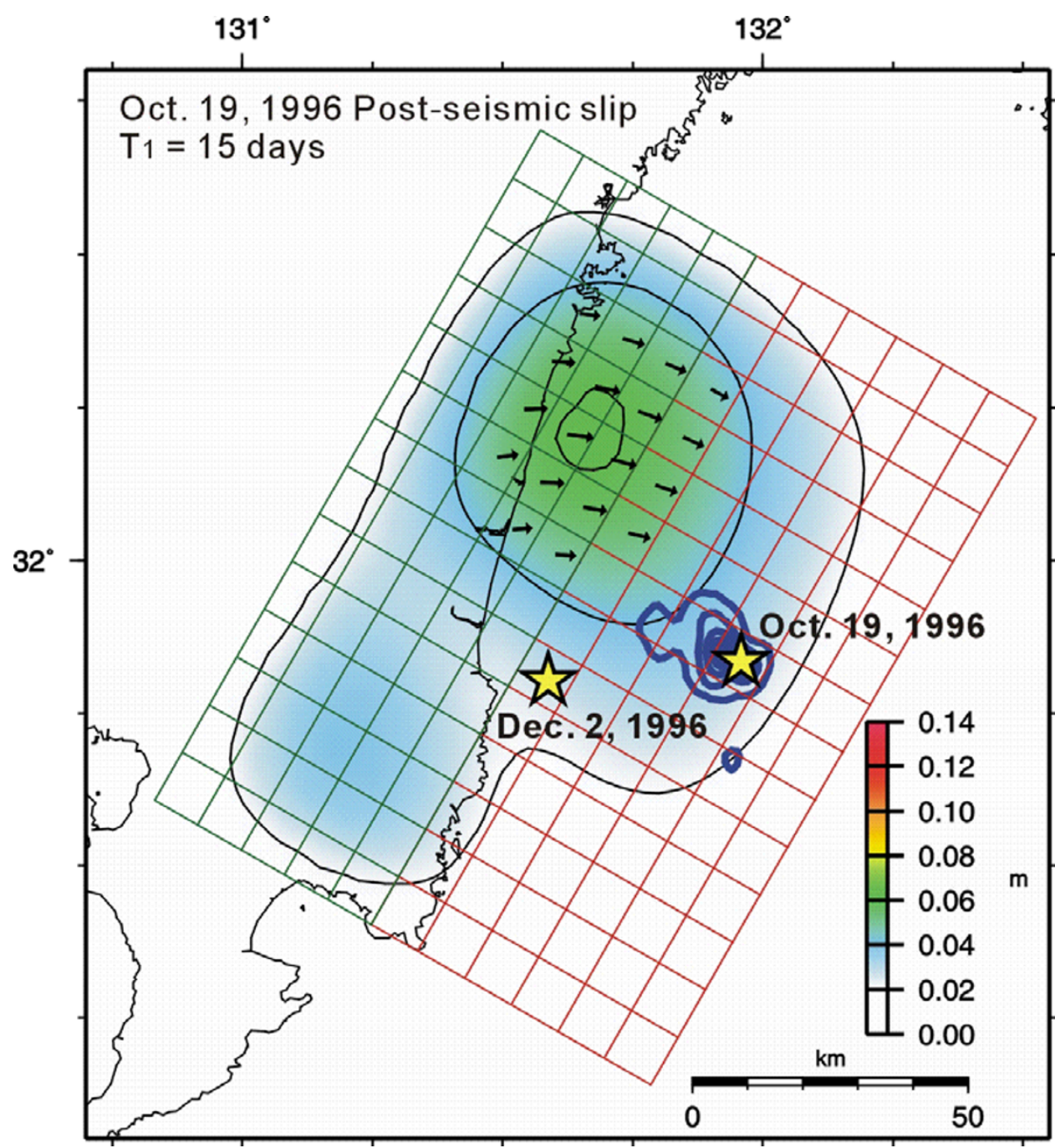

Fig. 8. Map view of the post-seismic slip for the Hyuga-nada earthquake of October 1999. The contour interval of post-seismic slip is 0.02 m. Blue contours denote the co-seismic slip for Hyuga-nada earthquake of October. The contour interval of co-seismic slip is $0.5 \mathrm{~m}$.

seismic displacement, $X_{5 j}$ is always zero. Also, because the May Kagoshima earthquake was not followed by a postseismic event, $Y_{4 j}$ is zero.

For given values of $T_{i}, \tau$, and $\sigma$, we can estimate $X, Y$, $A$, and $B$ using the linear least squares method. Grid-search is made to estimate the characteristic time $T_{i}$ using good quality data only. We assumed the value of scale parameters $(\tau, \sigma)=\left(4 \mathrm{~mm} /\right.$ year $\left.^{(1 / 2)}, 10 \mathrm{~mm}\right)$ and obtained the results that $T_{1}=15, T_{2}=100, T_{3}=30$, and $T_{5}=100$ (days).

Based on these parameters and Eq. (5), the displacements for individual events are shown in Fig. 6. Co-seismic displacements of the two Hyuga-nada earthquakes $\left(X_{1 j}\right.$ and $X_{2 j}$ ) were directed southeast (Figs. 6(a), (c)). The amplitude decreases with epicentral distance. Post-seismic displacements $\left(Y_{1 j}\right.$ and $\left.Y_{2 j}\right)$ were also directed east or southeast (Figs. 6(b), (d)). The amplitude also decreases with epicentral distance. For each earthquake, the decay rate of the post-seismic slip is smaller than that of the co-seismic slip, indicated that the depth range of post-seismic slips is deeper than that of co-seismic slips. At a glance, the post-seismic displacement of the first earthquake seems to be similar to that of the second earthquake. However, the NS component is slightly different between these cases, indicating that slip occurred in different regions.

Co-seismic displacements due to the Kagoshima earthquakes of March $\left(X_{3 j}\right)$ and May $\left(X_{4 j}\right)$ reveal a common pattern, as shown in Figs. 6(e) and (g). The post-seismic displacement after the March earthquake $\left(Y_{3 j}\right)$ is similar to the co-seismic displacements, as shown in Fig. 6(f). On the other hand, the slow slip component $\left(Y_{5 j}\right)$ has a different pattern in that the displacement in northern Kyushu is larger than that in southern Kyushu (Fig. 6(h)). Such a displacement pattern is consistent with the previous result obtained by Hirose et al. (1999). It is inferred that the slow event source must be located beyond the northern end of the other source areas. Precise analysis of this component will be made in a separate paper.

The linear trend component $\left(B_{j}\right)$ is shown in Fig. 6(i). The pattern of displacement vectors is again quite different between the northern and southern areas of Kyusyu. The overall features are fairly consistent with crustal movement during a period of 1891-1982 obtained by the GSI network (Tada, 1985). 


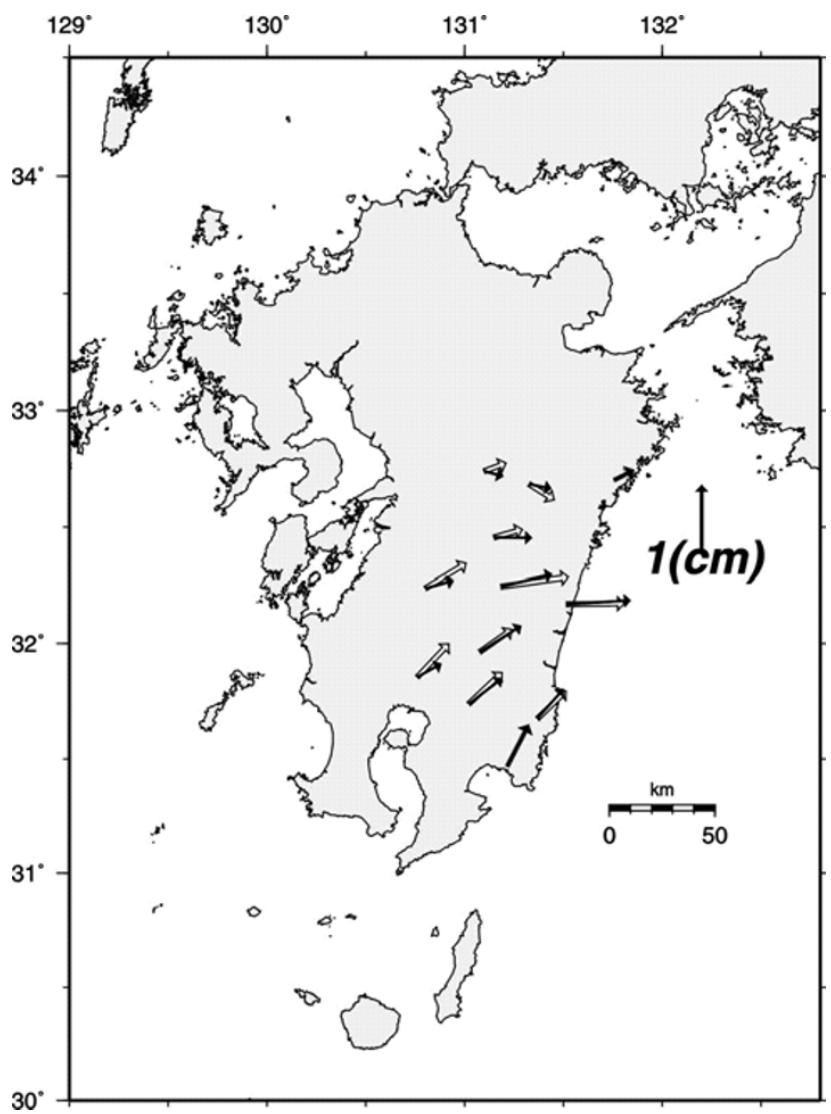

Fig. 9. Comparison of the observed displacements (open arrows) and the synthetic ones (closed arrows) for the post-seismic slip after the Hyuga-nada earthquake of October.

\section{Source Inversion}

Using the post-seismic displacements derived from GPS data, we determine the causative fault motions. We employ an inversion method originally developed by Yoshida et al. (1996) and slightly modified here. We assume that postseismic slips occur on the plate boundary. The fault plane is divided into sub-faults, where slip vectors are represented by a linear combination of the two orthogonal components. The increase of model parameters may give rise to instability on the solution in the sense that a small change in observed records would result in a large change in the solution. To stabilize the solution, we here impose a smoothness constraint on the slip distribution. Thus, we give the objective function, minimized in the inversion as follows:

$$
S=\sum_{j}\left[X_{j}-\sum_{m n k} D_{m n k} F_{m n k j}\right]^{2}+\beta^{2} \sum_{m n k}\left(\nabla^{2} D_{m n k}\right)^{2}
$$

where $D_{m n k}$ and $F_{m n k j}$ are the $k$-th component of the unknown slip vector at the $m n$-th subfault and the corresponding Green's function for the $j$-th station, respectively, $\nabla^{2}$ is the Laplacian operator, and $\beta$ is the relative weight of the constraints. To determine the value of $\beta$ objectively, we adopted the minimum Akaike's Bayesian information criterion (ABIC) (Akaike, 1980). ABIC value is defined by

$$
\begin{aligned}
\mathrm{ABIC}= & \left(K_{d}+K_{m}-K_{m}\right) \log S-K_{m} \log \beta^{2} \\
& +\log \left|\mathbf{A}^{T} \mathbf{A}+\beta^{2} \mathbf{R}^{T} \mathbf{R}\right|+C,
\end{aligned}
$$

where $K_{d}=$ number of data points, $K_{m}=$ number of model parameters, $\mathbf{A}=$ matrix of the Green's function, $\mathbf{R}=$ matrix of the Laplacian operator, and $C=$ a constant independent of $\beta$. The minimum ABIC method has been successfully applied to various inversion problems (e.g. Yoshida, 1989; Yabuki and Matsu'ura, 1992; Ide et al., 1996). We calculated Green's function for each segment using the computer program written by Yabuki and Matsu'ura (1992) based on Maruyama's (1964) formulations.

For the configuration of the plate boundary between the Philippine Sea Plate and the Eurasian Plate, we considered the spatial distribution of micro-earthquakes obtained by Kyushu University and the fault plane solution of the Oct. and Dec. Hyuga-nada earthquakes determined by Yagi et al. (1999). The fault plane for the two mainshocks is given by $($ strike, $\operatorname{dip})=\left(210^{\circ}, 12^{\circ}\right)$. Assuming that the plate boundary is a continuation of this fault plane, we put an additional fault segment denoted by B which is connected to the mainshock fault plane denoted by A (Fig. 7). The fault area of segment A and segment B are $140 \times 60 \mathrm{~km}^{2}$ and $140 \times 50$ $\mathrm{km}^{2}$, respectively, and they are divided into sub-faults with an equal area of $10 \times 10 \mathrm{~km}^{2}$. We tried to determine the dip angle of the fault segment by grid search, and obtained the dip angle of $25^{\circ}$. The fault segment $B$ is shallower than the seismicity zone associated with the downgoing PHS plate.

\section{Results}

Figure 8 shows the post-seismic slip following the Hyuganada earthquake of October 19,1996 . Slip vectors are mainly directed southwest. The direction is nearly coincident with the co-seismic slip obtained by Yagi et al. (1999), and is consistent with plate motion as proposed by Seno (1993). On the other hand, the major slip occurs outside the co-seismic slip area. The maximum slip is $0.06 \mathrm{~m}$ at about $50 \mathrm{~km}$ northwest of the main shock epicenter. The moment release is $1.7 \times 10^{19} \mathrm{Nm}(M w=6.8)$ where a rigidity of $\mu=40 \mathrm{GPa}$ is assumed. This value is comparable to the co-seismic moment release of $2.3 \times 10^{19} \mathrm{Nm}$. The characteristic time $\left(T_{1}\right)$ is 15 days. Figure 9 compares the observed displacements with synthetics. The overall feature is well reconstructed by the present model.

Figure 10 shows the post-seismic slip following the Hyuga-nada earthquake of December 2, 1996. Slip vectors are mainly directed southwest, which direction is similar to that of the post-seismic slip of the first earthquake. The major slip occurs in a deeper area than the co-seismic source area obtained by Yagi et al. (1999). The maximum slip of $0.13 \mathrm{~m}$ is found $15 \mathrm{~km}$ northwest of the main shock epicenter. The moment release is $2.0 \times 10^{19} \mathrm{Nm}(M w=6.8)$, which is larger than the co-seismic moment release of $1.5 \times 10^{19}$ $\mathrm{Nm}$ obtained by Yagi et al. (1999). The characteristic time $\left(T_{2}\right)$ is 100 days, which is longer than that of the previous post-seismic event. Figure 11 compares the observed displacements with synthetics. The overall waveform match is satisfactory.

\section{Discussion}

\section{Spatial distribution of moment release}

Figure 12 summarizes the post-seismic slips obtained in this paper, the co-seismic slip, fore-shocks, and aftershocks. 


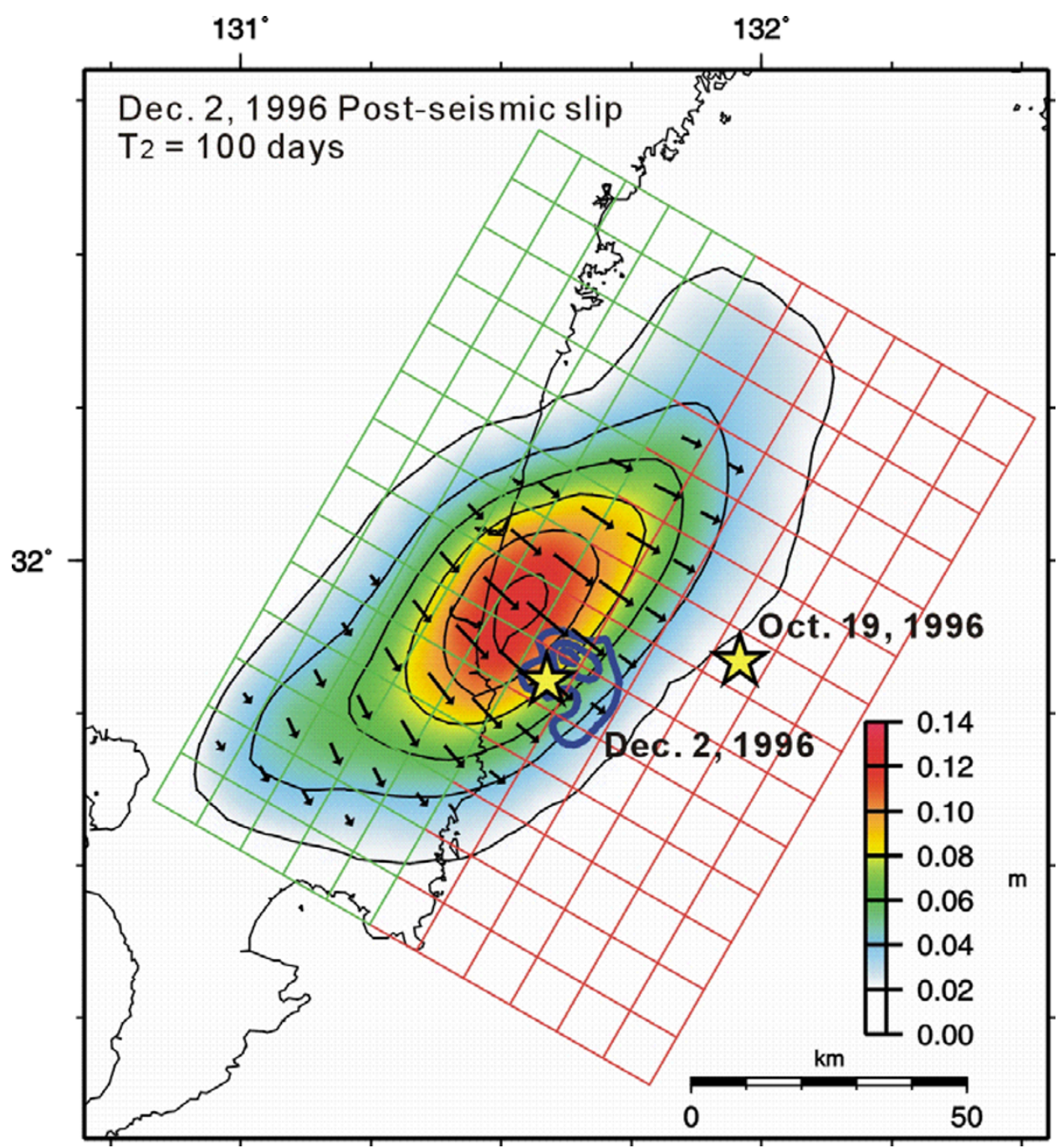

Fig. 10. Map view of the post-seismic slip for the Hyuga-nada earthquake of December 1996. The contour interval of post-seismic slip is $0.02 \mathrm{~m}$. Blue contours denote the co-seismic slip for Hyuga-nada earthquake of December. The contour interval of co-seismic slip is $0.5 \mathrm{~m}$.

It can be seen from this figure that the co-seismic slip areas of these events do not overlap. A similar feature was observed in the 1976 Imperial Valley earthquake. Scholz (1990) pointed out that the post-seismic slip was restricted to the top several kilometers of the sedimentary layer, where dynamic slip was impeded.

Our results suggest a sequence of fault motions as follows. The post-seismic slip was triggered in an area surrounding the fault plane of the first main shock. It rapidly developed a shear stress concentration at an edge of its slip area, and triggered the second large earthquake. The sites of co-seismic slip, post-seismic slip, and aftershocks share a plate boundary region in a complementary fashion. These sites may have their own constitutive laws, which may control individual modes of moment release as well as the entire event sequence. Post-seismic slip may play an important role especially in the interaction of such compound earthquakes.

Depth extent

The depth extent of moment release due to co-seismic and post-seismic slip is shown in Fig. 13. The co-seismic slip is restricted to a depth range of 13 to $23 \mathrm{~km}$ where the oceanic plate subducts with a shallow dip angle, while the post-seismic slip extends to a depth of $40 \mathrm{~km}$ where the subducting plate has a steep dip angle. Similar features were observed in the 1946 Nankai earthquake (Thatcher and Rundle, 1984) and the 1994 Far Off Sanriku earthquake (Nishimura, 1997).

The depth extent of co-seismic slip must be controlled by the transition from unstable slip to stable slip. Moreover, according to laboratory experiments, temperature is the most important factor in the stability of slip (Scholz, 1998). Our result indicates that the lower limit of the seismogenic zone in Hyuga-nada is significantly shallower than that in ordinary subduction zones, which is, say, $45 \mathrm{~km}$ (Scholz, 1998). This shallowness may support the warmer plate model in this area proposed by Peacock and Wang (1999).

\section{Conclusion}

We used continuous GPS data to examine the post-seismic slips associated with two large earthquakes in 1996 in Hyuganada, Japan. We found that the moment releases due to postseismic events are comparable with the co-seismic moments, and that the sites of co-seismic slip, post-seismic slip, and aftershocks do not overlap so much but share a plate bound- 


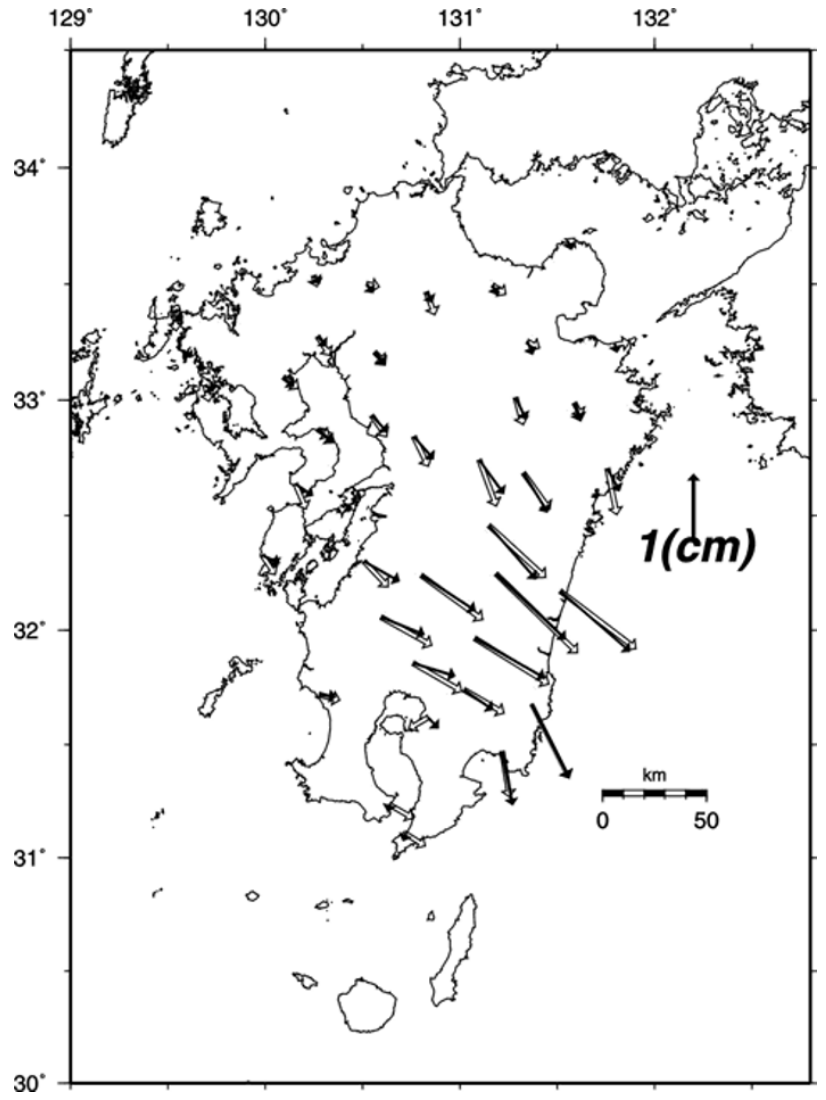

Fig. 11. Comparison of the observed displacements (open arrows) and the synthetic displacements (closed arrows) for the Hyuga-nada earthquake of December.

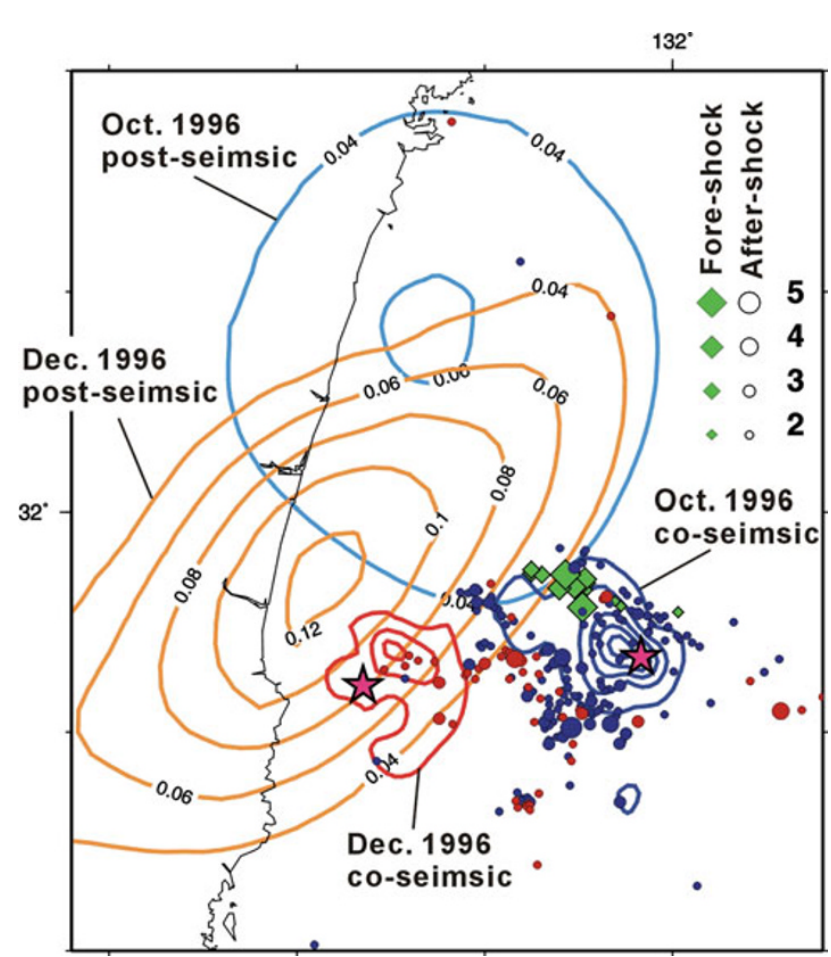

Fig. 12. Foreshocks (green diamonds), one-week aftershocks (blue circles) of the Hyuga-nada earthquake of October 1996, and one-week aftershocks (red circles) of the Hyuga-nada earthquake of December 1996. Blue and sky blue contours denote the co-seismic slip and the post-seismic slip, respectively, of the former earthquake. Red and orange contours denote the co-seismic slip and the post-seismic slip, respectively, of the latter earthquake. The contour interval of co-seismic slip is $0.5 \mathrm{~m}$.

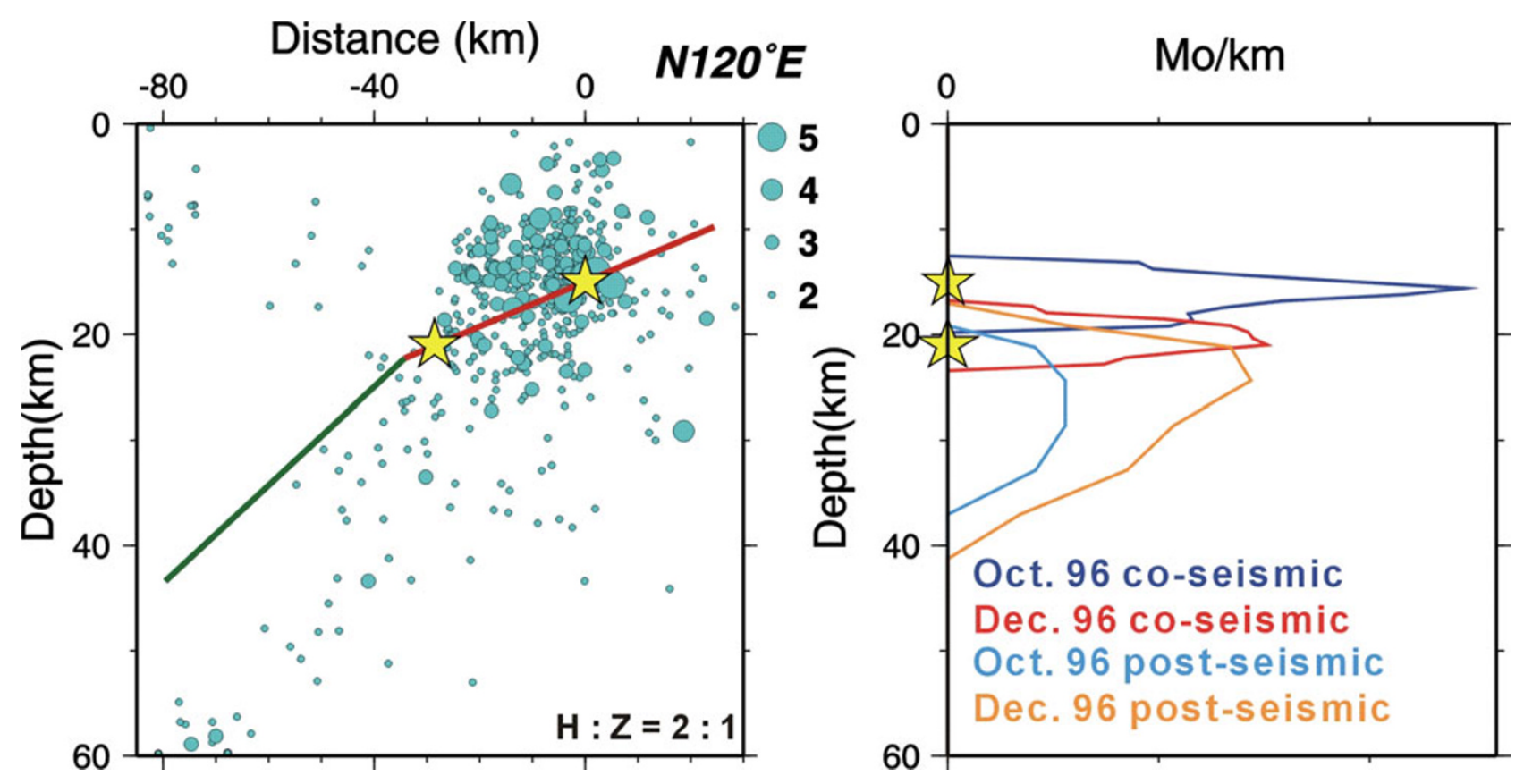

Fig. 13. Depth range of moment releases due to main shocks and post-seismic events. Left plate shows the cross-section of the background seismicity in the Hyuga-nada region and the plate boundary determined by this study. Right plate shows the co-seismic and post-seismic slips for the two Hyuga-nada earthquakes. 
ary region in a complementary fashion. We infer that these individual sites have their own constitutive laws of frictional sliding, and these laws control the occurrence and features of earthquakes.

Acknowledgments. We express our gratitude to Dr. Ross S. Stein and Dr. Fred Pollitz for their critical reviews. We also thank Mr. U. Uehira of the Shimabara Earthquake and Volcano Observatory, Faculty of Science, Kyushu University who provided hypocenter information. This study was partly supported by the Grant-in-Aid for Scientific Research (B) 10640399, from the Ministry of Education, Culture, Sports, Science and Technology, Japan. Y. Yagi is a JSPS Research Fellow.

\section{References}

Akaike, H., Likelihood and bayes procedure, in Bayesian Statistics, edited by J. M. Bernardo, M. H. DeGroot, D. V. Lindley, and A. F. M. Smith, pp. 143-166, University Press, Valencia, Spain, 1980.

Heki, K., S. Miyazaki, and H. Tsuji, Silent fault slip following an interplate thrust earthquake at the Japan trench, Nature, 386, 595-598, 1997.

Hirose, H., K. Hirahara, F. Kimata, N. Fujii, and S. Miyazaki, A slow thrust slip event following the two 1996 Hyuganada earthquakes beneath the Bungo Channel, southwest Japan, Geophys. Res. Lett., 26, 3237-3240, 1999.

Ide, S., M. Takeo, and Y. Yoshida, Source process of the 1995 Kobe earthquake: determination of spatio-temporal slip distribution by Bayesian modeling, Bull. Seism. Soc. Am., 86, 547-566, 1996.

Langbein, J. and H. Johnson, Correlated errors in geodetic time series: implications for time-dependent deformation, J. Geophys. Res., 102, 591603, 1997.

Maruyama, T., Static elastic dislocation in an infinite and semi-infinite medium, Bull. Earthq. Res. Inst., 42, 289-368, 1964.

Nishimura, T., The Spatiotemporal Distribution of Coseismic and Postseismic Slip Associated with the 1994 Far Off Sanriku Earthquake, M. Sc. Thesis, University of Tohoku, 1997.

Peacock, S. M. and K. Wang, Seismic consequences of warm versus cool subduction metamorphism: examples from southwest and northeast Japan, Science, 286, 937-939, 1999.

Scholz, C. H., The Mechanics of Earthquake and Faulting, pp. 314-317, Cambridge University Press, New York, 1990.

Scholz, C. H., Earthquake and friction laws, Nature, 391, 37-42, 1998.
Segall, P., R. Burgmann, and M. Matthews, Time-dependent triggered afterslip following the 1989 Loma Prieta earthquake, J. Geophys. Res., 105, 5615-5634, 2000.

Seno, T., S. Stein, and A. D. Gripp, A model for motion of the Philippine Sea Plate consistent with NUVEL-1 and Geological Data, J. Geophys. Res., 98, 17941-17948, 1993.

Shen, Z., D. D. Jackson, Y. Feng, M. Cline, M. Kim, P. Fang, and Y. Bock, Postseismic deformation following the Landers Earthquake, California, 28 June 1992, Bull. Seism. Soc. Am., 84, 780-791, 1994.

Smith, S. W. and M. Wyss, Displacement on the San Andreas fault subsequent to the 1966 Parkfield earthquake, Bull. Seis. Soc. Am., 58, 19551973,1968

Stein, R. S. and M. Lisowski, The 1979 Homestead valley earthquake sequence, California: control of aftershocks and postseismic deformation, J. Geophys. Res., 88, 6477-6490, 1983.

Tada, T., Spreading of the Okinawa Trough and its relation to the crustal deformation in the Kyushu (2), Zishin, 38, 1-12, 1985 (in Japanese).

Tada, T., T. Sagiya, and S. Miyazaki, Crustal deformation in the Japan Islands by using GPS network, Kagaku, 67, 917-927, 1997 (in Japanese).

Thatcher, W. and J. B. Rundle, A viscoelastic coupling model for the cyclic deformation due to periodically repeated earthquakes at subduction zones, J. Geophys. Res., 89, 1984.

Wyatt, F. K., Displacement of surface monuments: horizontal motion, $J$. Geophys. Res., 87, 979-989, 1982.

Wyatt, F. K., Displacement of surface monuments: vertical motion, J. Geophys. Res., 94, 1655-1664, 1989.

Yabuki, T. and M. Matsu'ura, Geodetic data inversion using a Bayesian information criterion for spatial distribution of fault slip, Geophys. J. Int., 109, 363-375, 1992.

Yagi, Y., M. Kikuchi, S. Yoshida, and T. Sagiya, Comparison of the coseismic rupture with the aftershock distribution in the Hyuga-nada earthquakes of 1996, Geophys. Res. Lett., 26, 3161-3164, 1999.

Yoshida, S., Waveform inversion using ABIC for the rupture process of the 1983 Hindu Kush earthquake, Phys. Earth Planet. Inter, 56, 389-405, 1989.

Yoshida, S., K. Koketsu, B. Shibazaki, T. Sagiya, T. Kato, and Y. Yoshida, Joint inversion of near- and far-field waveforms and geodetic data for rupture process of the 1995 Kobe earthquake, J. Phys. Earth, 44, 437454, 1996.

Y. Yagi (e-mail: yuji@eri.u-tokyo.ac.jp), M. Kikuchi, and T. Sagiya 